\title{
Antibiotic prescribing for acute respiratory tract infections in the United States outpatient setting
}

\author{
Amy L. Shaver ${ }^{1 *}$ D, David M. Jacobs ${ }^{2}$, Michael J. LaMonte ${ }^{1}$ and Katia Noyes ${ }^{1}$
}

\begin{abstract}
Background: Acute respiratory tract infections (ARIs) are common in the outpatient setting. Although they are predominantly viral, antibiotics are often prescribed for the treatment of ARIs.

Methods: Using the U.S. Medical Expenditure Panel Survey (MEPS; 2010-2015), we estimated the national prevalence and predictors of outpatient antibiotic prescribing for ARIs by provider type. We categorized the trends of antibiotic prescriptions (overall or broad-spectrum) for ARIs by provider type (physician and advanced practice provider [APP] which includes nurse practitioner [NP], and physician assistant [PA]). The outcome variable was defined as receipt of an antibiotic prescription during a consultation with a provider for an ARI (including outpatient clinic visit or doctor's office visit).

Results: There were 64,081,892 ARI antibiotic prescriptions written, with a decrease from 10.9 (2010) to 9.7 million (2015) during the study interval $(p<0.0001)$. Associations of patient- and provider-level variables with antibiotics prescription were examined using binary logistic regression. Blacks were more likely to receive antibiotics than whites (OR 1.51; $95 \% \mathrm{Cl} 1.25,1.84 ; p<0.001)$, and antibiotic prescription was more likely if the patient-provider race was concordant (OR 5.41; $95 \% \mathrm{Cl} 4.65,6.29, p<0.0001)$. Although the majority of patients with ARI were cared for by physicians, APPs were seeing an increasing number of ARI patients.

Conclusions: Antibiotic prescribing for ARls though declining, remains high. More research is needed to better understand the drivers of ARI antibiotic prescribing and to develop targeted interventions for both patients and providers.
\end{abstract}

Keywords: Antibiotics, United States, General practice, Upper respiratory tract infection, outpatient

\section{Background}

Antibiotic resistance is a major public health concern, and its development is primarily due to the overuse, or inappropriate use, of antibiotics [1,2]. Compounding the problem of antibiotic resistance is the fact that new antibiotics are not available quickly enough to mitigate antibiotic resistance at the population level [2, 3]. As concerns over antibiotic resistance increase, the demand for new antibiotics has also increased [4]. Antibiotic stewardship refers to "coordinated interventions designed to improve and measure the appropriate use of

\footnotetext{
* Correspondence: amyshave@buffalo.edu

${ }^{1}$ Department of Epidemiology and Environmental Health, School of Public Health and Health Professions, University at Buffalo, 272 Farber Hall, South Campus, Buffalo, NY 14260, USA

Full list of author information is available at the end of the article
}

an agent by promoting the selection of the optimal drug regimen including dosing, duration of therapy, and route of administration [2]". Within the policy set forth by the Society for Healthcare Epidemiology of America are recommendations including: that stewardship be required by regulation, that it be monitored in the ambulatory care (outpatient) setting, that providers and patients be educated on stewardship practices, and that stewardship research be completed [2]. Given the paucity of novel agents, stewardship efforts are increasing and their implementation encouraged in order to make best use of available antibiotics and limit the spread of antibiotic resistance [5]. A direct means of decreasing inappropriate antibiotic use would be to decrease inappropriate antibiotic prescribing. This could be done through the

(c) The Author(s). 2019 Open Access This article is distributed under the terms of the Creative Commons Attribution 4.0 International License (http://creativecommons.org/licenses/by/4.0/), which permits unrestricted use, distribution, and reproduction in any medium, provided you give appropriate credit to the original author(s) and the source, provide a link to the Creative Commons license, and indicate if changes were made. The Creative Commons Public Domain Dedication waiver (http://creativecommons.org/publicdomain/zero/1.0/) applies to the data made available in this article, unless otherwise stated. 
development of outpatient antibiotic stewardship programs including both patient and provider education on the dangers of inappropriate antibiotic prescribing.

Anywhere between 20 and $50 \%$ of the antibiotic prescribing in the United States outpatient setting is thought to be unnecessary; however, stewardship programs are not as prevalent in the outpatient setting as they are in the inpatient setting [2,6-11]. Acute respiratory tract infections (ARIs) are common in the outpatient setting and usually do not require an antibiotic as they tend to be viral [12]. ARIs describe a range of conditions including acute bronchitis, nasopharyngitis, sinusitis, influenza, and often the symptoms associated with the common cold [12]. Patients with ARIs are often prescribed antibiotics, which can lead to increased antibiotic resistance [13]. Population-level surveillance may be preferred and viable method to systematically monitor antibiotic use for appropriateness $[14,15]$.

The prevalence of antibiotic prescriptions written by physician assistants and nurse practitioners have increased [11]. According to the Pew Charitable Trusts, the majority of antibiotics in the outpatient setting are prescribed by family-care physicians (41\%), closely followed by physician assistants and nurse practitioners (23\% combined) [16]. Knowing which providers are more likely to prescribe antibiotics as well as for what indication (such as ARIs) is critical for the development of effective and sustainable outpatient stewardship programs. Therefore, the objectives of this study were twofold: (i) to provide an estimate of antibiotic prescribing for ARIs by provider group in the outpatient setting in the United States from 2010 to 2015 and (ii) to evaluate patient- and prescriber-level variables associated with prescribing antibiotics for ARIs.

\section{Methods}

\section{Data source}

The Medical Expenditure Panel Survey (MEPS) took its current form in 1996 and is administered by the Agency for Healthcare Research and Quality (AHRQ) [17]. MEPS participants are sampled from a subset of households who participated in the previous year's National Health Interview Survey (NHIS). Respondents provide information over up to 2.5 years and five survey rounds (spaced 5-6 months apart); this information covers two years' worth of a respondent's information. MEPS oversamples from Hispanics, African Americans, Asians, and low-income individuals to increase the precision of generated estimates [17].

The current study utilized full-year consolidated household component files which contain expenditure and utilization data for the calendar year from several rounds of data collection. The household component includes the prescribed medicines file, which contains both medicine names and National Drug Codes (NDC) for all prescriptions. Prescription information, including NDC, is verified with the patient's pharmacy. The prescribed medicines file also includes conditions associated with the medication, the start date of the medication, total expenditure, and sources of payment. Conditions are defined by truncated International Classification of Disease, 9th Revision, Clinical Modification (ICD-9-CM) codes, the truncated codes protect the privacy of survey participants. Trained professional coders complete the MEPS coding and determine the appropriate diagnosis code based on verbatim text from the participant. One respondent provides information for an entire household, and the consolidated full-year dataset, associated files, documentation, and codebooks are available through the AHRQ website [17].

\section{Study design and definitions}

We analyzed outpatient ARI antibiotic prescribing categorized by provider from 2010 to 2015. Conditions of interest were those considered viral ARIs and were identified by ICD-9-CM and Clinical Classification System (CCS) codes. When a CCS code included a bacterial diagnosis, the more specific ICD-9-CM code was used. Events for inclusion were those with diagnosis codes for acute nasopharyngitis, ARI, acute bronchitis and bronchiolitis, laryngitis and tracheitis, influenza, and viral pneumonia.

ARI events were examined for antibiotic use. Antibiotic classes were identified using the NDC directory and generic names. Broad-spectrum antibiotics were defined based on the National Committee for Quality Assurance's (NCQA) Antibiotics of Concern list and included quinolones, macrolides (azithromycin and clarithromycin), amoxicillin/clavulanate, ketolides (oral telithromycin), cephalosporins (2nd and 3rd generations), and clindamycin [11, 18-20]. Providers were categorized into two groups based on who the patient reported having seen during the healthcare visit. Those designated as medical doctor, doctor of osteopathy, or other medical specialty (surgeon, rheumatologist, etc.) were placed in the physician category. Nurse practitioners and physician assistants were collapsed into a single category, advanced practice provider (APP). As a provider could not be ascertained, 169,920,972 (26.9\%) visits were excluded from the analysis.

\section{Variables of interest}

Variables of interest were determined through literature review. Demographic variables included age, gender, race, geographic location, and income. Income was categorized as above and below the median for the sample (except in the regression analysis where it was kept as a continuous variable), and insurance coverage was 
categorized as private, public, or none. Race was described as a categorical variable including: White, Black, Asian, and Other. Geographic location was included as it can help bring to light regional variations in provider practice and its categorization is based on the US Census geographic regions: Northeast, South, Midwest, and West. Provider types were categorized as physician and APP as above. A race dyad was included to indicate whether the race of the provider was the same as the patient, with race determined based on respondents' answers to survey questions. Number of comorbidities was included as a proxy of general health status. MEPS includes codes for fifteen distinct comorbidities (attention deficit hyperactivity disorder, angina, joint pain, high blood pressure, arthritis, emphysema, diabetes, elevated cholesterol, coronary heart disease, chronic bronchitis, cancer, asthma, history of stroke, history of heart attack, and other heart disease). A further patient characteristic included was an SF-12 indicator, the SF-12 being a population health measure and a suitable measure of self-reported health status in epidemiological studies (SF-12 is a 12-question short form) [21-23].

\section{Data and statistical analysis}

Antibiotic prescription prevalence was defined as the percentage of ARI events wherein an antibiotic was prescribed; the prevalence was further expressed as the percent of ARI events wherein a broad-spectrum antibiotic was prescribed. A sensitivity analysis was conducted by comparing prevalence of antibiotic prescribing for ARI among the overall group and a new group wherein comorbidities that were considered likely to warrant antibiotic use including mastoiditis, otitis media, soft tissue infection, urinary tract infection, chronic obstructive pulmonary disease, human immunodeficiency virus/acquired immunodeficiency syndrome, cystic fibrosis, and diabetes mellitus were removed. As the two analyses showed no meaningful difference, those with the aforementioned comorbidities were retained for all analyses. (See Additional file 1.)

Multivariable binomial logistic regression was performed to determine factors associated with ARI antibiotic prescribing by provider type. The outcome of interest was receipt of an antibiotic prescription for ARI. The exposures of interest included multiple patient and provider characteristics including: patient age, patient sex, patient race, patient insurance coverage, number of patient comorbidities, patient income level, patient geographical location, and a patient-provider race dyad. As a further exploration of race, each homogenous group was compared against those visits where a concordant race dyad did not exist. The reference group for each exposure was determined based on literature review or lack of characteristic (in the case of the race dyad).
Trend analyses year to year were performed utilizing a chi-square statistic. All statistical analyses were carried out utilizing the weighting as provided by AHRQ and using the survey procedures available in SAS version 9.4 (SAS Institute, Cary, NC).

\section{Results}

\section{Antibiotic receipt categorized by demographics}

During the study period (2010-2015) there were 461, 647,174 visits to providers associated with a ARI diagnosis (Table 1). Females were more frequently seen by a provider for a ARI than males, and therefore females were more frequently prescribed an antibiotic for ARI $(62.42 \%$ vs. $37.58 \%)$. Those aged under 10 years accounted for the majority of visits (21.53\%), and the percentage of ARI visits receiving an antibiotic were highest in the Southern region of the US (42.24\%). As the number of comorbidities increased (a possible indication of poorer health), the number of antibiotics prescribed for a ARI decreased. Likewise, a higher SF-12 which indicates the patient believes they are in good health, was associated with an increased percentage of antibiotic receipt (above average: 39.05\%, below average $25.06 \%$ ). Physicians wrote $94.19 \%$ of antibiotic prescriptions for ARI visits compared to $5.81 \%$ written by advanced practice providers (nurse practitioners and physician assistants). Among whites seen for ARI, 48.9\% saw a white provider whereas among Asian ARI visits, $39.7 \%$ saw an Asian provider and among blacks seen for ARI, $12.3 \%$ saw a black provider.

\section{ARI antibiotic receipt trends categorized by year and provider}

A total of 67,974,312 ARI antibiotic prescriptions were dispensed during the study period, with an approximately 10\% decrease from 2010 to 2015 (Table 2). The number of ARI visits increased during the study period from 70.6 million in 2010 to 82.4 million in 2015. Although a majority of ARI visits are managed by a physician that number is slowly decreasing as more ARI visits are managed by both nurse practitioners and physician assistants (Fig. 1). The percentage of ARI visits where an antibiotic was prescribed has decreased from $2010(15.5 \%)$ to $2015(11.8 \%)$ as has the percent of ARI visits where a broad-spectrum antibiotic was prescribed (Table 2, Fig. 2).

The percentage of ARI visits where an antibiotic was prescribed categorized by the type of provider seen is presented in Table 3. Among ARI visits managed by a physician $15.2 \%$ received an antibiotic, with $9.4 \%$ of visits receiving a broad-spectrum antibiotic. Among those visits managed by an advanced practice provider (a category made up of nurse practitioners and physician 
Table 1 Study population characteristics of patients with ARIs based on being prescribed an antibiotic ${ }^{a}$

\begin{tabular}{|c|c|c|c|}
\hline Characteristic Total $n=461,647,174(100 \%)$ & Prescribed antibiotic $n=67,974,312(14.7 \%)$ & Not prescribed antibiotic $n=393,672,862(85.3 \%)$ & $p^{c}$ \\
\hline Sex & & & 0.0825 \\
\hline Male $n=181,521,291$ (39.3\%) & $25,543,444(37.58 \%)$ & $155,977,847(39.62 \%)$ & \\
\hline Female $n=280,125,884(60.7 \%)$ & $42,430,868(62.42 \%)$ & $237,695,016(60.38 \%)$ & \\
\hline Age (years) & & & 0.0647 \\
\hline Under $10 n=110,656,003$ (23.9\%) & $14,635,674(21.53 \%)$ & $96,020,329$ (24.39\%) & \\
\hline $10-19 n=56,838,785(12.3 \%)$ & $7,772,409(11.43 \%)$ & $49,066,377(12.46 \%)$ & \\
\hline $20-29 n=37,182,206(8.1 \%)$ & $5,274,446(7.76 \%)$ & $31,907,759(8.11 \%)$ & \\
\hline $30-39 n=47,768,926(10.3 \%)$ & $7,550,521(11.11 \%)$ & $40,218,405(10.22 \%)$ & \\
\hline $40-49 n=51,518,968(11.2 \%)$ & $8,492,247(12.49 \%)$ & $43,026,721(10.93 \%)$ & \\
\hline $50-59 n=68,657,383(14.9 \%))$ & $10,492,186(15.44 \%)$ & $58,165,197(14.78 \%)$ & \\
\hline $60-69 n=55,017,935(11.9)$ & $8,304,438(12.22 \%)$ & $46,713,497(11.87 \%)$ & \\
\hline $70-79 n=22,470,007(4.9 \%)$ & $3,692,925(5.43 \%)$ & $18,777,082(4.77 \%)$ & \\
\hline$\geq 80 \mathrm{n}=11,536,962(2.5 \%)$ & $1,759,465(2.59 \%)$ & $9,777,496(2.48 \%)$ & \\
\hline Race & & & $<0.0001$ \\
\hline White $n=392,701,683$ (85.1\%) & $60,176,049(88.53 \%)$ & $332,525,634(84.47 \%)$ & \\
\hline Black $n=34,685,841$ (7.5\%) & $3,965,300(5.83 \%)$ & $30,720,541(7.80 \%)$ & \\
\hline Asian $n=15,916,805$ (3.4\%) & $1,630,550(2.40 \%)$ & $14,286,255(3.63 \%)$ & \\
\hline Other $n=18,342,845$ (4.0\%) & $2,202,413(3.24 \%)$ & $16,140,432(4.10 \%)$ & \\
\hline Region & & & 0.0042 \\
\hline Northeast $n=76,084,919$ (16.5\%) & $11,525,183(16.96 \%)$ & $64,559,736(16.40 \%)$ & \\
\hline Midwest $n=103,118,002$ (22.3\%) & $17,331,387(25.50 \%)$ & $85,786,615$ (21.79\%) & \\
\hline West $n=84,054,804(18.2 \%)$ & $10,403,926(15.31 \%)$ & $73,650,879(18.71 \%)$ & \\
\hline South $n=198,177,099$ (42.9\%) & $28,713,816(42.24 \%)$ & $169,463,283(43.05 \%)$ & \\
\hline Family income & & & 0.0413 \\
\hline$\$ 0-\$ 68,571 n=231,258,378(50.1 \%)$ & $32,547,281(47.88 \%)$ & $198,711,097(50.48 \%)$ & \\
\hline$\geq \$ 68,571 n=230,388,796(49.9 \%)$ & $35,427,031(52.12 \%)$ & $194,961,766(49.52 \%)$ & \\
\hline Insurance coverage & & & 0.0030 \\
\hline Any private $n=343,417,418$ (74.4\%) & $53,106,220(78.13 \%)$ & $290,311,198(73.74 \%)$ & \\
\hline Public only $n=100,535,778$ (21.8\%) & $12,460,230(18.33 \%)$ & $88,075,548(22.37 \%)$ & \\
\hline Uninsured $n=17,693,978$ (3.8\%) & $2,407,861$ (3.54\%) & $15,286,117(3.88 \%)$ & \\
\hline Medicare Eligible & & & 0.0530 \\
\hline Yes $n=57,709,393(12.5 \%)$ & $9,367,275(13.78 \%)$ & $48,342,118(12.28 \%)$ & \\
\hline No $n=403,937,782$ (87.5\%) & $58,607,037$ (86.22\%) & $345,330,745(85.49 \%)$ & \\
\hline Comorbidities & & & 0.1114 \\
\hline $0 n=197,076,466(42.7 \%)$ & $27,548,817(40.53 \%)$ & $169,527,649(43.06 \%)$ & \\
\hline $1 n=91,760,462(19.9 \%)$ & $13,417,990(19.74 \%)$ & $78,342,471$ (19.90\%) & \\
\hline $2 n=61,345,949(13.3 \%)$ & $9,941,271(14.63 \%)$ & $51,404,678(13.06 \%)$ & \\
\hline $3 n=50,259,383(10.9 \%)$ & $8,283,590(12.19 \%)$ & $41,975,793(10.66 \%)$ & \\
\hline $4 n=28,513,861(6.2 \%)$ & $4,156,770(6.12 \%)$ & $24,357,091(6.19 \%)$ & \\
\hline 5 or more $n=32,691,054(7.1 \%)$ & $4,625,874(6.81 \%)$ & $28,065,180(7.13 \%)$ & \\
\hline SF-12 (only $\geq 18$ years old) & & & 0.0009 \\
\hline Below average $n=167,250,051$ (36.2\%) & $17,033,112(25.06 \%)$ & $103,297,923(26.24 \%)$ & \\
\hline Average $n=21,250,631(4.6 \%)$ & $24,397,901$ (35.89\%) & $154,427,749(39.23 \%)$ & \\
\hline Above average $n=162,490,490(35.2 \%)$ & $26,543,299$ (39.05\%) & $135,947,191(34.53 \%)$ & \\
\hline
\end{tabular}


Table 1 Study population characteristics of patients with ARIs based on being prescribed an antibiotic ${ }^{\text {(Continued) }}$

\begin{tabular}{lll}
\hline Characteristic Total $n=461,647,174(100 \%)$ & Prescribed antibiotic $n=67,974,312(14.7 \%)$ & Not prescribed antibiotic $n=393,672,862(85.3 \%)$ \\
\hline Prescriber type & & \\
APP $n=40,158,044(8.7 \%)$ & $3,950,115(5.81 \%)$ & $36,207,929(9.20 \%)$ \\
MD $n=421,489,131(91.3 \%)$ & $64,024,197(94.19 \%)$ & $357,464,934(90.08 \%)$ \\
Race same as provider & & $<0.0001$ \\
Yes $n=202,777,280(43.9 \%)$ & $51,003,278(75.03 \%)$ & $151,774,002(38.55 \%)$ \\
No $n=258,869,894(56.1 \%)$ & $16,971,034(24.97 \%)$ & $241,898,861(61.45 \%)$ \\
White $n=192,129,340(41.6 \%)^{d}$ & $49,216,309(72.4 \%)$ & $8,034,694(2.0 \%)$ \\
Black $n=4,258,487(0.92 \%)^{d}$ & $783,968(1.2 \%)$ & $621,015(0.16 \%)$ \\
Asian $n=6,326,667(1.4 \%)^{d}$ & $997,969(1.5 \%)$ & $961,236(0.24 \%)$ \\
Not concordant $n=258,869,894(56.1 \%)^{d}$ & $16,971,034(24.97 \%)$ & $241,898,861(61.45 \%)$ \\
\hline
\end{tabular}

Abbreviations: $A R I$ acute respiratory tract infection, $P A$ physician assistant, NP nurse practitioner, MD physician, SF-12 short form-12

${ }^{a}$ All data presented as both weighted frequency $(\mathrm{n})$ and proportions of patients (\%)

${ }^{\mathrm{b}}$ Comorbidities include: attention deficit hyperactivity disorder, angina, joint pain, high blood pressure, arthritis, emphysema, diabetes, elevated cholesterol,

coronary heart disease, chronic bronchitis, cancer, asthma, history of stroke, history of heart attack, and other heart disease

${ }^{c} p$-value represents results of $\mathrm{X} 2$ for categorical values and $t$-test for continuous variables

d Percentages do not sum to 100 as the 'other' category was too small to include

assistants) $9.8 \%$ received an antibiotic and 5.4\% received a broad-spectrum antibiotic.

\section{Factors associated with ARI antibiotic receipt}

Factors associated with antibiotic prescription during a ARI visit are presented in Table 4. Black patients were more likely than their white counterparts to receive an antibiotic for a ARI diagnosis (OR 1.51; 95\% CI 1.25, 1.84). Although the South saw more cases of ARI those in the Midwest had a $18 \%$ greater odds of antibiotic receipt for ARI than those in the South (OR 1.18; 95\% CI $1.01,1.38)$. Those with an above average SF-12 score were $21 \%$ more likely to have received an antibiotic for ARI (OR 1.21; 95\% CI 1.03, 1.42). As comorbidity increased, odds of antibiotic receipt decreased insignificantly (OR 0.97; 95\% CI 0.93, 1.01). Those ARI events managed by physicians as compared to those managed by advanced practice providers (nurse practitioners and physician assistants) were at an increased odds of antibiotic receipt (OR 1.36; 95\% CI 1.13, 1.65). The odds of ARI antibiotic receipt were increased when the race of the patient matched the race of the provider (OR 5.41;
95\% CI 4.65, 6.29). Odds varied depending on whether the concordant race was White, Black or Asian compared to odds in non-concordant pairs (OR 3.98; 95\% CI 1.96, 8.08; OR 2.61; 95\% CI 1.21, 5.65; OR 2.23; 95\% CI $1.06,4.69$, respectively).

The results of a sensitivity analysis, not shown, comparing prevalence of antibiotic prescribing for ARI among the overall group and a new group wherein comorbidities that were considered likely to warrant antibiotic use including mastoiditis, otitis media, soft tissue infection, urinary tract infection, chronic obstructive pulmonary disease, human immunodeficiency virus/acquired immunodeficiency syndrome, cystic fibrosis, and diabetes mellitus were removed, indicated no meaningful difference between the groups in regards to population characteristics nor proportion of antibiotic prescribing. (See Additional file 1.)

\section{Discussion}

The purpose of this study was to determine the prevalence of antibiotic prescribing categorized by provider type, as well as to examine if any factors were associated

Table 2 Annual ARI prevalence categorized by year, type of provider seen, and antibiotic receipt ${ }^{a}$

\begin{tabular}{lllllll}
\hline Year & 2010 & 2011 & 2012 & 2013 & 2014 & 2015 \\
\hline ARI Visits & $70,564,592$ & $70,866,608$ & $73,615,067$ & $78,723,720$ & $85,523,707$ & $82,353,481$ \\
Physician & $66,303,919(93.9 \%)$ & $66,680,009(94.1 \%)$ & $67,972,755(92.3 \%)$ & $71,130,678(90.4 \%)$ & $75,152,677(87.9 \%)$ & $74,249,092(90.2 \%)$ \\
Nurse practitioner & $2,939,945(4.2 \%)$ & $2,665,883(3.8 \%)$ & $4,037,377(5.5 \%)$ & $4,477,586(5.7 \%)$ & $6,999,795(8.2 \%)$ & $5,094,616(6.2 \%)$ \\
Physician assistant & $1,320,728(1.9 \%)$ & $1,520,716(2.2 \%)$ & $1,604,9352.2 \%)$ & $3,115,456(3.9 \%)$ & $3,371,235(3.9 \%)$ & $3,009,773(3.7 \%)$ \\
Received any antibiotic & $10,927,504(15.5 \%)$ & $12,176,720(17.2 \%)$ & $10,087,197(13.7 \%)$ & $12,463,573(15.8 \%)$ & $12,570,746(14.7 \%)$ & $9,748,572(11.8 \%)$ \\
Received broad-spectrum & $7,013,417(9.9 \%)$ & $7,308,493(10.3 \%)$ & $5,988,583(8.1 \%)$ & $7,805,243(9.9 \%)$ & $8,260,365(9.7 \%)$ & $5,329,877(6.5 \%)$ \\
\hline
\end{tabular}

Abbreviations: $A R I$ acute respiratory tract infection

a Data presented as number of ARI visits, and number of visits (\%)

Broad-spectrum includes: quinolones, macrolides (azithromycin and clarithromycin), amoxicillin/clavulanate, ketolides (oral telithromycin), cephalosporins (2nd and 3rd generations), and clindamycin 


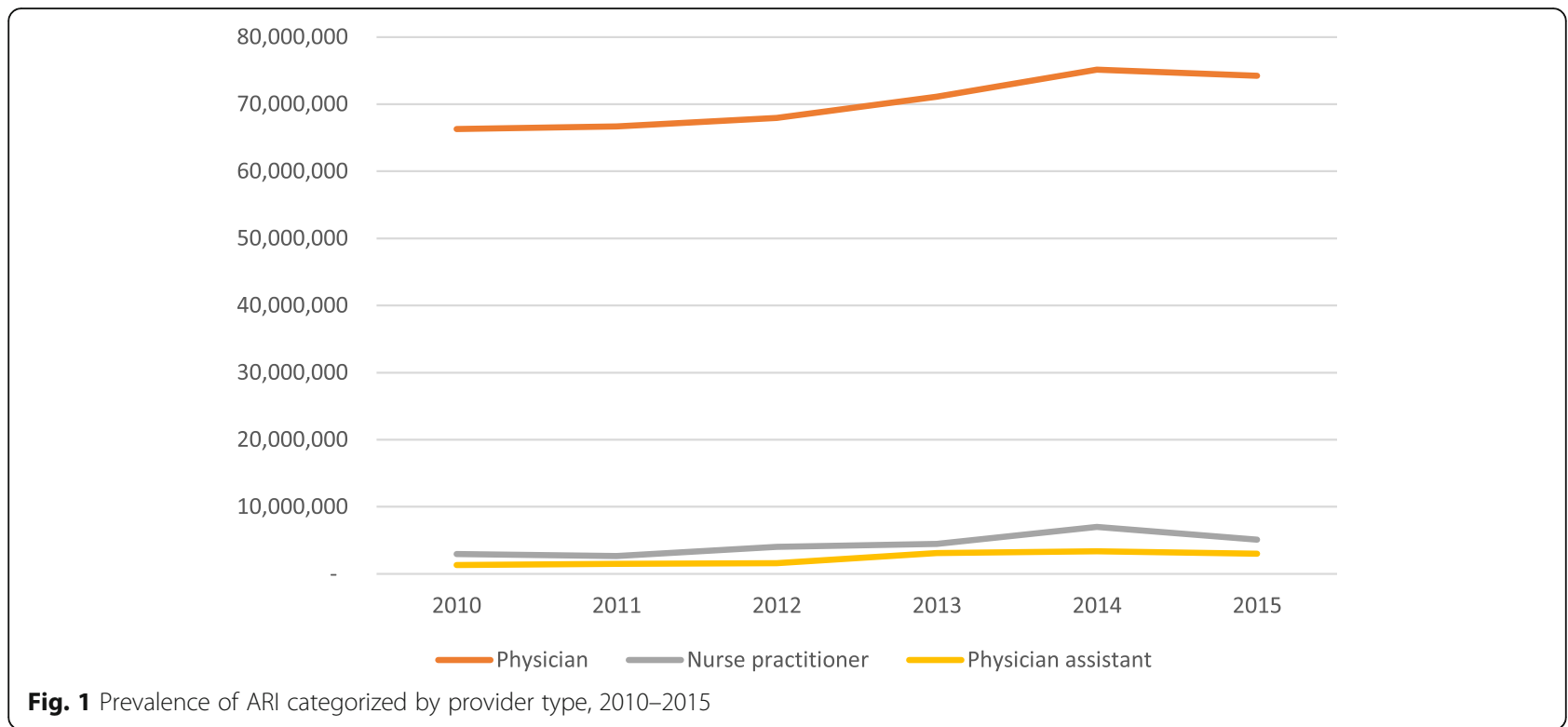

with ARI antibiotic prescribing. This study found that most antibiotics for ARI are prescribed by physicians. An increasing number of ARI cases are seen by APPs even though the vast majority of ARIs are seen by physicians. The authors found that racial disparities exist in antibiotic prescribing for ARI. Interestingly, the study found that when the race of the patient and provider was concordant the patient was more likely to be prescribed an antibiotic for ARI. It is heartening to see that antibiotic prescribing for ARI is decreasing, but it still remains at a high level.

Although physicians saw the majority of ARI cases over the study period, the percentage of ARI cases being seen by physicians decreased concurrently with an increase in the proportion of cases seen by nurse practitioners and physician assistants. This trend may be due to a number of related factors. Although the overall number of physicians has increased to serve the population, there has also been an increase in the number of physicians seeking specialization [24-26]. The physician to patient ratio in primary care settings has remained close to 50 primary care physicians per 100,000 persons from 1980 through 2010 regardless of federal government incentives to increase the number of communitybased primary care physicians $[24,27]$. It has also been suggested that the relatively lower salary and a medical educational culture that fosters specialization would need to change in order to recruit and train enough

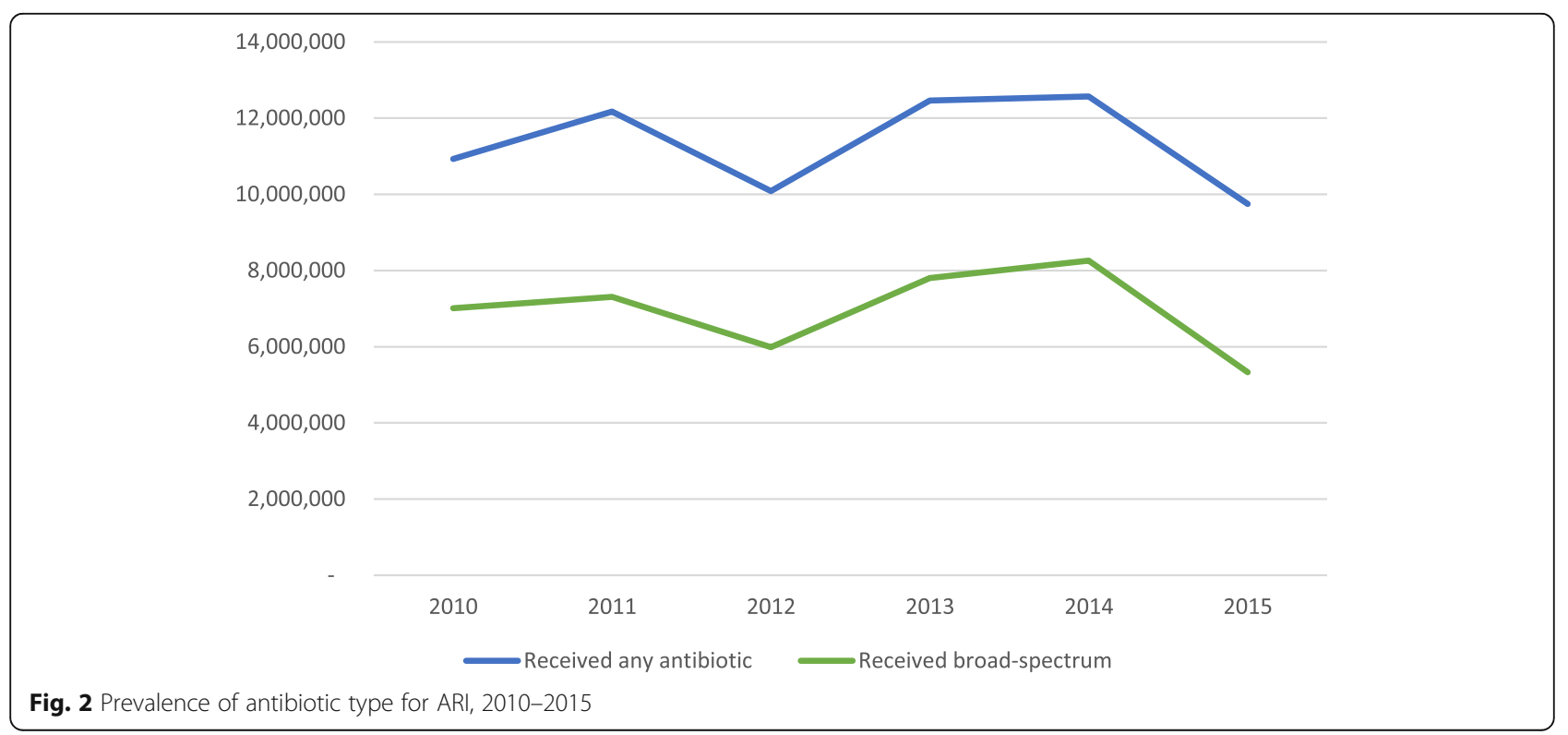


Table 3 ARI antibiotics categorized by provider seen from 2010 to 2015

\begin{tabular}{lll}
\hline Provider type & Physician $^{\mathrm{a}}$ & Advanced practice provider $^{\mathrm{b}}$ \\
\hline Antibiotic prescribed & $64,024,197(15.2 \%)$ & $3,950,115(9.8 \%)$ \\
Broad-spectrum prescribed & $39,535,243(9.4 \%)$ & $2,170,736(5.4 \%)$
\end{tabular}

Abbreviation: $A R I$ acute respiratory tract infection

${ }^{a}$ Data presented as number of physician ARI visits where an antibiotic was prescribed followed by percent of physician visits where an antibiotic was prescribed

${ }^{b}$ Data presented as number of advanced practice provider (APP) ARI visits where an antibiotic was prescribed followed by percent of APP visits where an antibiotic was prescribed

Broad-spectrum includes: quinolones, macrolides (azithromycin and clarithromycin), amoxicillin/clavulanate, ketolides (oral telithromycin), cephalosporins (2nd and 3rd generations), and clindamycin

primary care physicians to face the projected shortage [27-31]. Alongside a decrease in primary care physicians, there has been an upsurge in the number of retail clinics and urgent care centers following changes in non-physician practitioner scope of practice regulations [32]. The quality of care at retail clinics has been shown to be comparable to physician offices but at lower cost for the treatment of otitis media, pharyngitis, and urinary tract infections [33]. The combination of lower cost and convenience of appointment may account for the increase in ARI cases managed by APPs.

Antibiotic prescribing for ARIs remained relatively stable among physicians over the study period when considered as a percentage of ARI visits. Granted, a higher percentage of physician visits saw an antibiotic prescribed and a higher percentage of broad-spectrum antibiotic. However, this may be due to physicians seeing more complex patients at a later stage in the disease process. Among nurse practitioners and physician assistants, antibiotic prescribing for ARIs increased. The increase in antibiotic prescribing among APPs is consistent with previous findings. In a cross-sectional study using a nationally representative database covering 2005 to 2010, antibiotic prescribing rates decreased for physicians but increased by 3.2 and $3.4 \%$ among physician assistants and nurse practitioners, respectively [11]. Similarly, there has been an increase in broad-spectrum antibiotic prescribing for ARIs. Our findings show a significant increase in broad-spectrum prescribing among physician assistants, with a slight increase among nurse practitioners. Suda et al. reported a 15\% increase in broad-spectrum prescribing among APPs and a decrease among physicians [11]. Lee et al. performed an analysis of outpatient antibiotic prescribing using the MEPS database from 2000 to 2010 and found that broadspectrum prescribing doubled over that period [19]. Utilizing the National Ambulatory Medical Survey and the National Hospital Ambulatory Medical Care Survey, Roumie et al. showed that non-physician clinicians prescribe antibiotics more frequently in situations that are deemed inappropriate regardless of practice setting [34]. Antibiotic prescribing in the outpatient setting is critical to combatting antibiotic resistance [35].
There existed evidence of racial disparity in ARI antibiotic prescription receipt, with blacks more likely to receive an antibiotic than their white counterparts. Gerber et al. showed a decreased likelihood of antibiotic receipt among black children and, when prescribed an antibiotic, it was less likely to be broad-spectrum [36]. Goyal et al. described similar findings among non-Hispanic black children [37]. The current study examined both provider and patient race, which may account for the differing results. Race concordance between provider and patient was strongly associated with antibiotic receipt for an ARI. Though the strength of the association differed each concordant race pair was in the same direction away from the null. Other studies focusing on race examined the race of the patient but did not include the race of the provider [36]. The patient-provider relationship represents a complex interplay between the perceived wants of the patient or guardian and the perception by providers that a patient who does not 'get what they want' will not return to their practice [36]. It has previously been shown that although patients may sometimes desire an antibiotic when it is not warranted, the ability of a provider to accurately interpret a patient's desire for an antibiotic prescription and to predict this desire is flawed [38]. Mangione-Smith et al. showed that when a provider gave extra counseling regarding the lack of need for an antibiotic, most patients left a provider office satisfied with their experience [38]. Further research is warranted to examine the role race plays in the decision to prescribe an antibiotic for both the provider and patient.

This study found that those in the South had a higher prevalence of ARI office visits. Concurrently the patients seen in the Midwest were more likely to receive an antibiotic at a ARI office visit. Government figures indicate that the highest rates of antibiotic prescribing is in the South followed by the Midwest, however this is for all antibiotics and not only those for ARI [39]. This study also found that as number of comorbidities increased the odds of antibiotic decreased, though the finding was not significant. This could be due to different use of the healthcare system. The study also found that as a person's perception of their health status improved the odds of antibiotic receipt for ARI increased. In other words, 
Table 4 Factors associated with receipt of an antibiotic during a ARI visit ${ }^{a, b}$

\begin{tabular}{|c|c|c|c|}
\hline Characteristic & $O R^{a, b}$ & $95 \% \mathrm{Cl}$ & $p^{e}$ \\
\hline Age (years), continuous & 0.99 & $0.99,1.00$ & 0.0785 \\
\hline \multicolumn{4}{|l|}{ Sex } \\
\hline Female & 1.08 & $0.97,1.19$ & 0.1494 \\
\hline \multicolumn{4}{|l|}{ Male (ref) } \\
\hline \multicolumn{4}{|l|}{ Race } \\
\hline Black & 1.51 & $1.25,1.84$ & $<0.001$ \\
\hline Asian & 0.72 & $0.56,0.93$ & 0.0118 \\
\hline Other & 2.24 & $1.60,3.13$ & $<0.0001$ \\
\hline \multicolumn{4}{|l|}{ White (ref) } \\
\hline Comorbidities $^{c}$, continuous & 0.97 & $0.93,1.01$ & 0.1492 \\
\hline \multicolumn{4}{|l|}{ Region } \\
\hline Northeast & 1.03 & $0.87,1.21$ & 0.7421 \\
\hline Midwest & 1.18 & $1.01,1.38$ & 0.0411 \\
\hline West & 0.93 & $0.80,1.09$ & 0.3775 \\
\hline \multicolumn{4}{|l|}{ South (ref) } \\
\hline Income, continuous & 1.00 & $1.00,1.00$ & 0.4597 \\
\hline \multicolumn{4}{|l|}{ Insurance coverage } \\
\hline Any Private & 1.05 & $0.76,1.44$ & 0.7756 \\
\hline Any Public & 0.85 & $0.61,1.17$ & 0.3167 \\
\hline \multicolumn{4}{|l|}{ Uninsured (ref) } \\
\hline \multicolumn{4}{|l|}{ Medicare } \\
\hline Yes & 1.09 & $0.90,1.32$ & 0.3868 \\
\hline \multicolumn{4}{|l|}{ No (ref) } \\
\hline \multicolumn{4}{|l|}{ SF-12 } \\
\hline Above average & 1.21 & $1.03,1.42$ & 0.0190 \\
\hline Below average & 1.14 & $0.94,1.37$ & 0.1813 \\
\hline \multicolumn{4}{|l|}{ Average (ref) } \\
\hline \multicolumn{4}{|l|}{ Provider type } \\
\hline Physician & 1.36 & $1.13,1.65$ & 0.0016 \\
\hline \multicolumn{4}{|l|}{ APP (ref) } \\
\hline \multicolumn{4}{|l|}{ Concordant race ${ }^{d}$} \\
\hline Yes & 5.41 & $4.65,6.29$ & $<0.0001$ \\
\hline \multicolumn{4}{|l|}{ No (ref) } \\
\hline White & 3.98 & $1.96,8.08$ & 0.0002 \\
\hline Black & 2.61 & $1.21,5.65$ & 0.0153 \\
\hline Asian & 2.23 & $1.06,4.69$ & 0.0353 \\
\hline Not concordant (ref) & & & \\
\hline
\end{tabular}

Abbreviations: $A R I$ acute respiratory tract infection, $O R$ odds ratio, $\mathrm{Cl}$ confidence interval, APP advanced practice provider

${ }^{a}$ The odds compare those ARI visits where antibiotics were prescribed to those ARI visits where no antibiotic was prescribed

${ }^{\mathrm{b}}$ Each estimate is adjusted for all other variables in the table

c Comorbidities include: attention deficit hyperactivity disorder, angina, joint pain, high blood pressure, arthritis, emphysema, diabetes, elevated cholesterol coronary heart disease, chronic bronchitis, cancer, asthma, history of stroke, history of heart attack, and other heart disease

${ }^{d}$ Concordant race refers to the patient and provider being of the same race as reported by the patient

e $p$-value represents a test for significance of the odds ratio those who are in good health with a low number of comorbidities may only go to a provider when they are suffering from more 'everyday' complaints such as the common cold.

Viral infections do not benefit from treatment with an antibiotic. Prescribing an unwarranted medication increases the incidence of adverse drug events and leads to increased antibiotic resistance [40, 41]. Judicious use of antibiotics is currently a focus of inpatient antibiotic stewardship programs, and although there is a move towards stewardship in the outpatient setting, efforts need to be expanded and reinforced to decrease antibiotic prescribing and related expenditures [8, 42-45]. Expansion of such efforts can help to further decrease potentially unwarranted antibiotic prescribing. Patients need to be educated that an antibiotic is not always a necessity and, in some cases, may in fact cause harm. Clinicians need to reinforce the concept of appropriate antibiotic use with their patients and attempt to decrease their prescribing rate, particularly for viral indications [46]. A key component of antibiotic stewardship programs is continuing education and this should be provided to all clinicians [47]. This study has extended previous work by considering different factors that may be at play in the patient-provider relationship. Specifically, this study considered both patient and provider characteristics as factors associated with ARI antibiotic prescribing.

This study has several limitations. First, the study depended on ICD-9-CM and CCS codes from patient self-report, which could lead to misclassification of diagnosis leading to a misinterpretation of either a patient's comorbidities or of ARI. ARIs are typically viral in origin and previous studies removed visits from analysis where it was believed that patient comorbidities could more reasonably dictate an antibiotic prescription. Initial removal of these ARI visits from the current study population was done so as to clarify the results; in other words, by removing cases where it may be appropriate to find an antibiotic prescribed, we can rest more assured that where we find an antibiotic prescribed it is more likely to be inappropriate. It was determined that removal of those persons did not lead to a significant difference in the proportion of ARI visits where an antibiotic was prescribed and as such the study was conducted on all ARI visits where a provider could be determined. Second, within multi-provider practices, the clinician who signed off on a prescription may not be the provider who initially prescribed it. The MEPS Household component reports who the patient saw during their visit and concluded that the provider seen by the patient was the one who wrote the prescription. Regardless, we believe that our estimates provide a useful baseline of antibiotic prescribing for a common viral illness. A further 
limitation is the use of income as a marker of socioeconomic status versus the more robust marker years of education. This was done due to the inconsistency of the years of education variable across the study years in MEPS. The analysis was based on complete data of both the exposure and the outcome which caused the removal of approximately $27 \%$ of ARI cases for missing a provider which may have caused inaccuracy in the estimate. As an observational study, it is possible that estimates were inaccurate due to the presence of unmeasured confounders.

\section{Conclusions}

In conclusion, ARI antibiotic prescribing has decreased over the study period namely in the final year of the study. Though it is possible the difference seen in prescribing may not be a true reduction, only future study will tell if there are other factors at work that could have accounted for the differences observed. Racial differences in antibiotic prescribing were seen, especially when the race of the patient matched the race of the provider. Further research is necessary to determine the role that race plays in the patient-provider relationship with regards to antibiotic prescribing. Further, targeted stewardship programs should be developed to help decrease the potentially inappropriate prescribing habits of all providers.

\section{Additional file}

Additional file 1: Appendix 1. Sensitivity Analysis. Table S1. Population characteristics. (DOCX $20 \mathrm{~kb}$ )

\begin{abstract}
Abbreviations
AHRQ: Agency for Healthcare Research and Quality; APP: Advanced Practice Provider; ARI: Acute Respiratory Tract Infection; CCS: Clinical Classification System; Cl: Confidence Interval; ICD-9-CM: International Classification of Disease, 9th Revision, Clinical Modification; MD: Medical Doctor, physician; MEPS: Medical Expenditure Panel Survey; NCQA: National Committee for Quality Assurance; NDC: National Drug Code; NHIS: National Health Interview Survey; NP: Nurse Practitioner; OR: Odds Ratio; PA: Physician Assistant; SF: Short form
\end{abstract}

\section{Acknowledgements}

Not applicable.

\section{Authors' contributions}

AS Main idea conception, data analysis, manuscript writing and revision. DJ Advisement on drug information, editorial review of manuscript. KN Advisement on health services, editorial review of manuscript. ML Advisement on statistical analysis, editorial review of manuscript. All authors read and approved the final version of the manuscript.

\section{Funding}

Supported in part by Interdisciplinary Training in Cancer Epidemiology: T32CA113951. The funding body had no role in the design of the study and collection, analysis, and interpretation of data and in writing the manuscript.

\section{Availability of data and materials}

The datasets generated and/or analyzed during the current study are available in the AHRQ MEPS repository, https://meps.ahrq.gov/mepsweb/ data_stats/download_data_files.jsp.

Ethics approval and consent to participate

The study was waived for approval by the University at Buffalo Institutional Review Board.

\section{Consent for publication}

Not applicable.

\section{Competing interests}

The authors declare that they have no competing interests.

\section{Author details}

'Department of Epidemiology and Environmental Health, School of Public Health and Health Professions, University at Buffalo, 272 Farber Hall, South Campus, Buffalo, NY 14260, USA. ²Department of Pharmacy Practice, School of Pharmacy and Pharmaceutical Sciences, University at Buffalo, Buffalo, NY, USA.

Received: 14 December 2018 Accepted: 16 June 2019

Published online: 02 July 2019

\section{References}

1. Spellberg B, Guidos R, Gilbert D, Bradley J, Boucher HW, Scheld WM, et al. The epidemic of antibiotic-resistant infections: a call to action for the medical community from the Infectious Diseases Society of America. Clin Infect Dis. 2008;46(2):155-64.

2. Society for Healthcare Epidemiology of America. Policy statement on antimicrobial stewardship by the Society for Healthcare Epidemiology of America (SHEA), the Infectious Diseases Society of America (IDSA), and the Pediatric Infectious Diseases Society (PIDS). Infect Control Hosp Epidemiol. 2012;33:322-7.

3. Spellberg B, Powers JH, Brass EP, Miller LG, Edwards JE Jr. Trends in antimicrobial drug development: implications for the future. Clin Infect Dis. 2004;38(9):1279-86.

4. Sertkaya A, Jessup A, Wong HH. Promoting antibacterial drug development: select policies and challenges. Applied health economics and health policy. 2017:15(1):113-8.

5. The White House. National action plan for combating antibiotic-resistant bacteria. Washington, DC: The White House; 2015.

6. Hooton TM, Levy SB. Antimicrobial resistance: a plan of action for community practice. Am Fam Physician. 2001;63(6):1087-98.

7. Centers for Disease Control and Prevention. Get smart: know when antibiotics work. Atlanta: Centers for Disease Control and Prevention; 1993. https://www.cdc.gov/antibiotic-use/week/index.html.

8. Tamma PD, Cosgrove SE. Addressing the appropriateness of outpatient antibiotic prescribing in the United States: an important first step. JAMA 2016:315(17):1839-41.

9. Gulani A, Sachdev HP, Qazi SA. Efficacy of short course ( $<4$ days) of antibiotics for treatment of acute otitis media in children: a systematic review of randomized controlled trials. Indian Pediatr. 2010:47(1):74-87.

10. Llewelyn MJ, Fitzpatrick JM, Darwin E, Tonkin-Crine S, Gorton C, Paul J, et al. The antibiotic course has had its day. BMJ. 2017;358:j3418.

11. Suda KJ, Roberts RM, Hunkler RJ, Taylor TH. Antibiotic prescriptions in the community by type of provider in the United States, 2005-2010. J Am Pharm Assoc. 2016;56(6):621 6.e1.

12. Mossad S. Upper respiratory tract infections. Cleveland: Cleveland Clinic; 2013. https://teachmemedicine.org/cleveland-clinic-upper-respiratory-tractinfections/.

13. Costelloe C, Metcalfe C, Lovering A, Mant D, Hay AD. Effect of antibiotic prescribing in primary care on antimicrobial resistance in individual patients: systematic review and meta-analysis. BMJ. 2010;340:c2096.

14. Kritsotakis El, Gikas A. Surveillance of antibiotic use in hospitals: methods, trends and targets. Clin Microbiol Infect. 2006;12(8):701-4.

15. Infectious Diseases Society of America. Bad bugs, no drugs: as antibiotic R\&D stagnates, a public health crisis brews. Alexandria, VA: Infectious Diseases Society of America; 2004. 
16. The PEW Charitable Trusts. Variation in outpatient antibiotic prescribing in the United States. Philadelphia, Pennsylvania: The PEW Charitable Trusts; 2016. https://www.pewtrusts.org/-/media/assets/2017/10/variation_in_ outpatient_antibiotic prescribing.pdf

17. Agency for Healthcare Research and Quality. Medical expenditure panel survey. Rockville: Agency for Healthcare Research and Quality; 2016. https:// meps.ahrq.gov/mepsweb/.

18. Hersh AL, Shapiro DJ, Pavia AT, Shah SS. Antibiotic prescribing in ambulatory pediatrics in the United States. Pediatrics. 2011;128(6):1053-61.

19. Lee GC, Reveles KR, Attridge RT, Lawson KA, Mansi IA, Lewis JS 2nd, et al. Outpatient antibiotic prescribing in the United States: 2000 to 2010. BMC Med. 2014;12:96.

20. National Committee for Quality Assurance. Antibiotics of concern. Washington, DC: National Committee for quality assurance; 2017. https:// www.ncqa.org/hedis/measures/hedis-2017-national-drug-code-ndc-license/ hedis-2017-final-ndc-lists/.

21. Burdine JN, Felix MR, Abel AL, Wiltraut CJ, Musselman YJ. The SF-12 as a population health measure: an exploratory examination of potential for application. Health Serv Res. 2000;35(4):885-904.

22. Vera-Villarroel P, Silva J, Celis-Atenas K, Pavez P. Evaluation of the SF-12: usefulness of the mental health scale. Rev Med Chil. 2014;142(10):1275-83.

23. Utah Department of Health. Interpreting the SF-12. Salt Lake City, Utah: Utah Department of Health; 2001. http://health.utah.gov/opha/publications/ 2001hss/sf12/SF12_Interpreting.pdf

24. Klink K. Incentives for physicians to pursue primary care in the ACA era. AMA J Ethics. 2015;17(7):637-46.

25. Petterson SM, Phillips RL Jr, Bazemore AW, Koinis GT. Unequal distribution of the US primary care workforce. Am Fam Physician. 2013;87(11):Online.

26. Hicks LA, Bartoces MG, Roberts RM, Suda KJ, Hunkler RJ, Taylor TH Jr, et al. US outpatient antibiotic prescribing variation according to geography, patient population, and provider specialty in 2011. Clin Infect Dis. 2015;60(9):1308-16.

27. Makaroff LA, Green LA, Petterson SM, Bazemore AW. Trends in physician supply and population growth. Am Fam Physician. 2013;87(7):Online.

28. Phillips JP, Petterson SM, Bazemore AW, Phillips RL. A retrospective analysis of the relationship between medical student debt and primary care practice in the United States. Ann Fam Med. 2014;12(6):542-9.

29. Rohan-Minjares F, Alfero C, Kaufman A. How medical schools can encourage students' interest in family medicine. Acad Med. 2015;90(5):553-5.

30. Colwill JM, Cultice JM, Kruse RL. Will generalist physician supply meet demands of an increasing and aging population? Health Aff (Millwood). 2008;27(3):w232-w41.

31. Bodenheimer T, Pham HH. Primary care: current problems and proposed solutions. Health Aff (Millwood). 2010;29(5):799-805.

32. Brooks Carthon JM, Sammarco T, Pancir D, Chittams J, Wiltse Nicely K. Growth in retail-based clinics after nurse practitioner scope of practice reform. Nursing outlook. 2017;65(2):195-201.

33. Mehrotra A, Liu H, Adams JL, Wang MC, Lave JR, Thygeson NM, et al. Comparing costs and quality of care at retail clinics with that of other medical settings for 3 common illnesses. Ann Intern Med. 2009;151(5):321-8.

34. Roumie CL, Halasa NB, Edwards KM, Zhu Y, Dittus RS, Griffin MR. Differences in antibiotic prescribing among physicians, residents, and nonphysician clinicians. Am J Med. 2005;118(6):641-8.

35. Sanchez GV. Core elements of outpatient antibiotic stewardship. MMWR Recommendations and reports : Morbidity and mortality weekly report Recommendations and reports / Centers for Disease Control 2016;65(6):1-12.

36. Gerber JS, Prasad PA, Localio AR, Fiks AG, Grundmeier RW, Bell LM, et al. Racial differences in antibiotic prescribing by primary care pediatricians. Pediatrics. 2013;131(4):677-84.

37. Goyal MK, Johnson TJ, Chamberlain JM, et al. Racial and Ethnic Differences in Antibiotic Use for Viral IIIness in Emergency Departments. Pediatrics. 2017;140(4)

38. Mangione-Smith R, McGlynn EA, Elliott MN, Krogstad P, Brook RH. The relationship between perceived parental expectations and pediatrician antimicrobial prescribing behavior. Pediatrics. 1999;103(4 Pt 1):711-8.

39. Control CfD, Prevention. Outpatient antibiotic prescriptions-United States 2015.

40. Cassir N, Di Marco JN, Poujol A, Lagier JC. Underestimated impact of antibiotic misuse in outpatient children. Arch Pediatr. 2012;19(6):579-84.

41. Shehab N, Patel PR, Srinivasan A, Budnitz DS. Emergency department visits for antibiotic-associated adverse events. Clin Infect Dis. 2008;47(6):735-43.

42. Suda KJ, Hicks LA, Roberts RM, Hunkler RJ, Danziger LH. A national evaluation of antibiotic expenditures by healthcare setting in the United States, 2009. J Antimicrob Chemother. 2013;68(3):715-8.
43. Tamma PD, Cosgrove SE. Antimicrobial stewardship. Infect Dis Clin N Am. 2011;25(1):245-60.

44. Fridkin SK, Srinivasan A. Implementing a strategy for monitoring inpatient antimicrobial use among hospitals in the United States. Clin Infect Dis. 2014 58(3):401-6.

45. Pollack L, Srinivasan A. Core elements of hospital antibiotic stewardship programs from the Centers for Disease Control and Prevention. Clin Infect Dis. 2014;59(Suppl 3):S97-100.

46. Lee CR, Lee JH, Kang LW, Jeong BC, Lee SH. Educational effectiveness, target, and content for prudent antibiotic use. Biomed Res Int. 2015;2015: 214021.

47. Ohl CA, Luther VP. Health Care Provider Education as a Tool to Enhance Antibiotic Stewardship Practices. Infect Dis Clin North Am. 28(2):177-93.

\section{Publisher's Note}

Springer Nature remains neutral with regard to jurisdictional claims in published maps and institutional affiliations.
Ready to submit your research? Choose BMC and benefit from:

- fast, convenient online submission

- thorough peer review by experienced researchers in your field

- rapid publication on acceptance

- support for research data, including large and complex data types

- gold Open Access which fosters wider collaboration and increased citations

- maximum visibility for your research: over $100 \mathrm{M}$ website views per year

At $\mathrm{BMC}$, research is always in progress.

Learn more biomedcentral.com/submissions 